\title{
GAMBARAN PERILAKU ORANG TUA DALAM STIMULASI PADA ANAK YANG MENGALAMI KETERLAMBATAN PERKEMBANGAN USIA 0-6 TAHUN
}

\author{
Dwi Haryanti ${ }^{1}$, Khatimul Ashom ${ }^{1}$, Qurrotul Aeni ${ }^{1}$ \\ ${ }^{1}$ Program Studi Ners, STIKES Kendal \\ ns.d.haryanti@gmail.com
}

\begin{abstract}
ABSTRAK
Perkembangan merupakan suatu perubahan yang tejadi pada anak yang dapat dilihat dari aspek motorik, emosi, kognitif dan psikososial interaksi anak terhadap lingkungan. Perkembangan anak paling pesat pada umur 0-6 tahun biasanyadisebut sebagai masa keemasaan atau the goldenages. Pada masa ini faktor stimulasi menjadi sangat penting dalam suatu perkembangan anak agar kemampuan anak terganggu meliputi perkembangan motorik halus, motorik kasar, bahasa dan kemampuan sosial. Tuhuan penelitian untuk mengetahui perilaku orang tua dalam menstimulasi anak usia 0-6 tahun di kecamatan Gringsing. Penelitian ini merupakan penelitian kuantitatif deskriftif dengan menggunakan pendekatan metode survey. Tehnik pengembalian sampel menggunakan purposive sampling dan didapatkan sampel sebanyak 65 responden. Alat penggumpulan data menggunakan kuesioner perilaku. Penelitian ini didapatkan hasilsebagian besar orang tua memiliki perilaku baik yaitu sebanyak 56 responden $(86,2 \%)$, sebagian kecil memiliki perilaku cukup yaitu sebanyak 9 responden $(13,8 \%)$ dan $235 \%$ responden belum melakukan motorik halus. Orang tua dapat mencari informasi tentang stimulasi perkembangan anak usia 0-6 tahun dengan jalan sering membaca buku, majalah, membuka internet bertanya kepada tenaga kesehatan, kader Posyandu, teman, atau keluarga untuk meningkatkan stimulasi perkembangan anak usia 0-6 tahun akan meningkat.
\end{abstract}

Kata kunci: Perilaku orangtua, stimulasi perkembangan anak

\section{IDENTIFIEDTHE BEHAVIOR OF PARENTS IN STIMULATING CHILDREN AGED 0-6 YEARS}

\begin{abstract}
Development a change that happen in children that can be seen from the motorik, emotional, cognitive and psychosocial aspects of the child's interaction with the environment. The most rapid child development at the age of 0-6 years is usually called as the golden age or the goldenages. At this time the stimulation factor becomes very important in a child's development so that the ability of children disturbed include the to development of soft motorik, coarse motorik, language and social ability. Objectiveb to identifiedthe behavior of parents in stimulating children aged 0-6 years in Gringsing district. This research descriptive quantitative research by using survey method approach. The technique of returning this sample with that purposive sampling and be found sample of 65 respondents. The instrument to collect data used questionnaire. This research got the result most parents have good behavior that as much 56 respondents 86,2\%), some have enough behavior which 9 respondents $(13,8 \%)$ and $335 \%$ of respondents have not done fine motor skills. Expected to find information about the stimulation of development of children aged 0-6 years by often reading books, magazines, opening the internet asking health workers, Posyandu cadres, friends, or family so that knowledge of developmental stimulation of children aged 0-6 years will increase.
\end{abstract}

Keywords: Parent behavior, Child development stimulation

\section{PENDAHULUAN}

Perkembangan merupakan suatu perubahan yang tejadi pada anak yang dapat dilihat dari aspek motorik, emosi, kognitif dan psikososial interaksi anak terhadap lingkungan (Harlimsyah, 2007). Perkembangan juga bertambahnya fungsi tubuh yang komplek dan teratur dapat diperkirakan dan diramalkan sebagai hasil proses dan diferensi sel,jaringan tubuh organ-organ dan sistemnya yang terorganisir (IDAI, 2002).

Perkembangan dimulai sejak dalam kandungan kemudian dilanjutkan ke 8 tahap mulai bayi (0 - 
18 bulan), toddler (1,5-3 tahun), anak-anak awal atau pra sekolah (3-6 tahun), sekolah (6-12 tahun), remaja (12-18 tahun), dewasa muda (18 - 35 tahun), dewasa tengah (35-65) tahun, dan tahap terakhir yaitu dewasa akhir ( $>65$ tahun), Erik Erikson dalam (Wong dkk, 2009). Periode emas anak disebut sebagai masa keemasaan atau the goldenages. Sebab pada masa itu otak akan sedang mengalami pertumbuhan dan perkembangan yang sangat pesat. Otak merupakan kunci utama bagi pembentukan kecerdasaan anak. Periode ini dimulai sejak janin dalam kandungan hingga usia 6 tahun. Perumbuhan dan perkembangan otak anak mencapai $80 \%$ dari otaknya di masa dewasa kelak. Artinya di atas periode ini, perkembangan otak hanya $20 \%$ saja. Selebihnya hanyalah perluasan permukaan otak dan janin dendrit yang lebih rumit (Suryadi, 2010).

Pertumbuhan otak terdapat periode tertentu dimana terdapat kesempatan yang baik jika dimanfaatkan atau resiko yang besar jika periode ini terlewatkan begitu saja. Pada periode kritis ini bagian otak tertentu masih sedang dalam masa pertumbuhan yang intensif dan flesibel, yang disebut juga " window of opportunity" atau " golden periods". Dengan adanya konsep periode kritis ini menunjukan bahwa awal kehidupan sangatlah penting dan sangat sulit untuk melakukan kompentensi apabila ada penglaman yang hilang di awal perkembangan. Oleh karena itu rangsangan/ stimulasi pada periode ini sangat berguna agar potensi anak dapat berkembang (Soetjiningsih, 2008).

Seorang anak dapat mengalami keterlambatan dan gangguan perkembangan. Angka kejadian gangguan perkembangan anak di seluruh dunia masih tergolong tinggi yaitu di Amerika Serikat bekisar $12-16 \%$, Thailand 24\%, Argentina 22\%, dan Indonesia 13-18\% (Hidayat, 2010). Di Provinsi Jawa Tengah cakupan Deteksi Dini TumbuhKembang (DDTK ) anak balita dan pra sekolah belum mencapai targetyang diharapkan terlihat data pada tahun 2007, cakupan DDTK anak balitadan prasekolah sebesar 35,66\% dengan kisaran antara yang terendah3,82\% di Kabupaten Kebumen. Hasil cakupan ditahun 2008 sebesar 44,7\% meningkat biladibandingkan dengan cakupan tahun 2007 . Cakupan tersebut masih jauhdibawah target tahun 2006 sebesar 75\% (Profil Kesehatan Jawa Tengah, 2008).

Berdasarkan data dari Profil Kesehatan Jawa Tengah tahun2009, cakupan deteksi dini tumbuh kembang anak balita dan pra sekolahtingkat Provinsi Jawa Tengah pada tahun 2009 sebesar 50,29\%, meningkatbila dibandingkan dengan cakupan tahun 2008 sebesar 44,76. Namun, halini masih harus mendapatkan perhatian serius dari pemerintah karenarencana strategi cakupan SDIDTK (Stimulasi Deteksi Intervensi Dini Tumbuh Kembang) Jawa Tengah tahun 2009 sebesar $90 \%$.

Fadlyana E, (2014) mengungkapkan pola keterlmbatan perkembangan balita di pedesaan dan perkotaan di Bandung dengan hasil balita yang mengalami keterlambatan perkembangan di daerah pedesaan sebesar $30 \%$ dan di perkotaan sebesar 19\%. Tjandrajani (2012) menemukan sebanyak $30,9 \%$ pasien baru yang datang di klinik khusus Tumbuh Kembang RSAB Harapan Kita mengalami keterlambatan Perkembangan Umum (KPU) dan 50,3\% nya adalah KPU tanpa penyakit penyerta dengan keluhan utama gangguan bicara.

Ada beberapa faktor yang mempengaruhi perkembangan pada anak yaitu keturunan, neuroendokrin, hubungan interpersonal, tingakat sosial ekonomi, penyakit, bahaya lingkungan, stess pada anak dan pengaruh media massa. Menurut hidayat, (2008) faktorfaktor yang mempengaruhi perkembangn anak antara lain adalah faktor henedler, faktor lingkungan pranatal dan faktor postnatal yang terdiri dari budaya, sosial ekonomi, nutrisi, iklim/cuaca, olahraga/latihan fisik, posisi anak dalam keluarga, status kesehatan dan faktor hormonal.

Menurut Susilaningrum dkk, (2013) ada dua faktor yang mempengaruhi pertumbuhan dan perkembangan anak yaitu faktor internal (genetic dan hormonal) dan faktor eksternal (faktor pranatal, internal dan postnatal) faktor pranatal meliputi: nutrisi ibu hamil, mekanis/posisi janin, toksin/zat kimia, kelainan endokrin, infeksi penyakit, kelainan imonologi dan psikologis ibu. Faktor intranatal meliputi: riwayat persalinan yang menyebabkan trauma kepala pada bayi sehingga menyebabkan kerusakan jaringan otak, seperti tindakan vacum ekstraksi dan forceps, dan faktor postnatal meliputi: gizi, penyakit kronis/kelainan kongenitakl, lingkungan fisik dan kimia, psikologis, obat-obatan, sosial ekonomi, lingkungan pengasuhan, stimulasi dan obatobatan. 
Faktor stimulasi menjadi sangat penting dalam suatu perkembangn anak. Stimulus orang tua dalam perkembangan anak adalah sebuah cara yang digunakan dalam proses interkasi yang berkelanjutan antara orang tua dan anak untuk membentuk hubungan yang hangat, dan memfasilitasi anak untuk mengembangkan kemampuan anak yang meliputi perkembangan motorik halus, motorik kasar, bahasa dan kemampuan sosial sesuai dengan tahap perkembanganya (Supartini, 2007).

Kurangya stimulasi dapat mengakibatkan keterlambatan perkembangan pada anak. Sebagian besar anak dengan keterlambatan perkembangan tidak teridentifikasi sampai usia pra sekolah atau usia sekolah sehingga membuat mereka kesulitan untuk mengembangkan potensi yang dimiiki (Grover D, Partnering. 2015). Stimulasi dapat merangsang perkembangan anak, untuk merangsang kemampuan dasar anak umur 0-6 tahun agar anak tumbuh dan berkembang secara optimal. Stimulasi dapat dilakukan setiap ada kesempatan dan sedini mungkin. Stimulasi ini harus di berikan secara rutin dan berkesinambungan dengan kasih sayang, metode bermain dan lain-lain. Sehingga perkembangan anak akan berjalan optimal (Dinkes, 2009). Stimulasi juga merupakan hal penting dalam tumbuh kembang anak, anak yang banyak mendapatkan stimulasi yang terarah dari orang tua akan lebih cepat berkembang dibandingkan anak yang kurang atau bahkan tidak mendapat stimulasi (Soetjiningsih, 2008). Oleh karena itu orang tua memiliki peran penting dalam menstimulasi perkembangan anak karena menjadi orang terdekat bagi anak. Stimulasi yang dilakukan orang tua dalam menunjang perkembangnya yaitu stimulasi kemampuan gerak kasar, stimulasi kemampuan gerak halus, stimulasi kemampuan bicara dan bahasa serta stimulasi kemampuan sosialisasi dan kemandirian (Sulistyawati, 2014).

Adapun orang tua juga harus mengetahui dan memahami cara-cara menstimulasi perkembangan anak agar dapat mencegah keterlambatan perkembangan(dinkes, 2009). Penting bagi orang tua untuk memahami berbagai faktor yang mempengaruhi perkembangan anak dan melakukan stimulasi perkembangan, khususnya perkembangan bagi anak usia 0-6 tahun dengan meningkatkan pengetahuan mereka dalam memberikan stimulasi (Sugeng seto,2009).

\section{METODE}

Jenis penelitian ini yaitukuantitatif dengan penelitian deskriptif menggunakan rancangan penelitian pendekatan survey. Sampel penelitian inijumlah populasi kurang dari 100, seluruh populasi dijadikan sampel penelitian. Sampel yang diambil dari penelitian ini adalah 65 orang tua. Penelitian ini menggunakan kuesioner. Analisa data menggunakan tendensi sentral dan distribusi frekuensi.

\section{HASIL}

Hasil penelitian dapat dilihat pada tabel berikut.

Tabel 1.

Usia Responden

\begin{tabular}{ccccccc}
\hline Karakteristik & Mean & Median & SD & Minimal & Maksimal & CI (95\%) \\
\hline Usia Ibu & 31,57 & 31,00 & 4,008 & 24 & 40 & $30,58-32,56$ \\
\hline Usia Ayah & 33,85 & 34,00 & 4,714 & 27 & 46 & $32,68-35,01$ \\
\hline
\end{tabular}

Tabel 3

Perilaku orang tua dalam Stimulasi Perkembangan

\begin{tabular}{lcc}
\hline Perilaku Orang tua & Frekuensi & Persentase $(\%)$ \\
\hline Baik & 56 & 86,2 \\
Cukup & 9 & 13,8 \\
Kurang & 0 & 0,0
\end{tabular}


Tabel 2.

Pekerjaan dan Pendidikan Responden

\begin{tabular}{lcccc}
\hline KarakteristikResponden & \multicolumn{2}{c}{ Ibu } & \multicolumn{3}{c}{ Ayah } \\
\cline { 2 - 5 } & $\mathrm{f}$ & $\%$ & $\mathrm{f}$ & $\%$ \\
\hline Pekerjaan & & & 54 & 83,1 \\
Bekerja & 36 & 55,4 & 11 & 16,9 \\
Tidak bekerja & 29 & 44,6 & & \\
\hline Pendidikan & & & 0 & 0,0 \\
SD & 0 & 0,0 & 5 & 7,7 \\
SMP & 11 & 16,9 & 53 & 81,5 \\
SMA & 54 & 83,1 & 7 & 10,8 \\
Sarjana & 0 & 0,0 & & \\
\hline
\end{tabular}

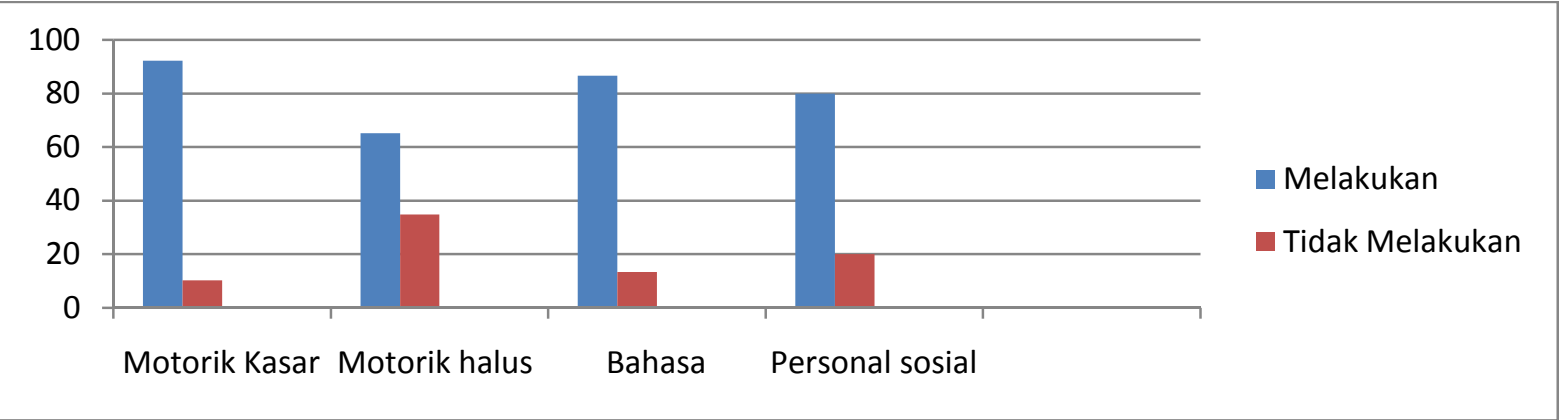

Gambar 1.

Persentase Perilaku Stimulasi Perkembangan Anak Usia 0-1 tahun

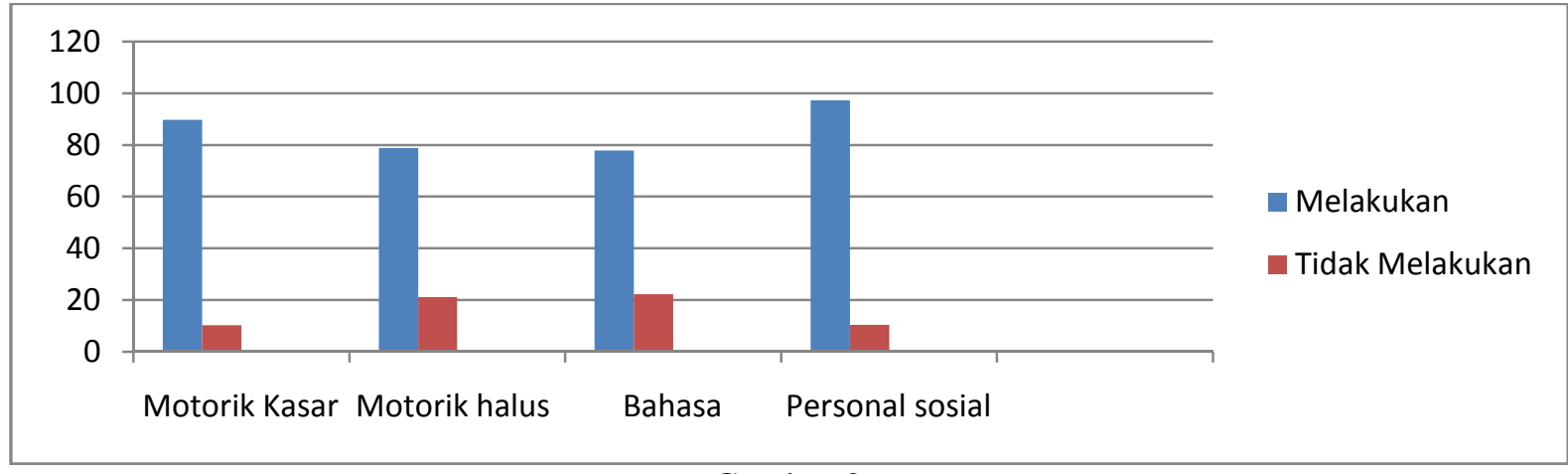

Gambar 2

Persentase Perilaku Stimulasi Perkembangn Anak Usia1-3 Tahun

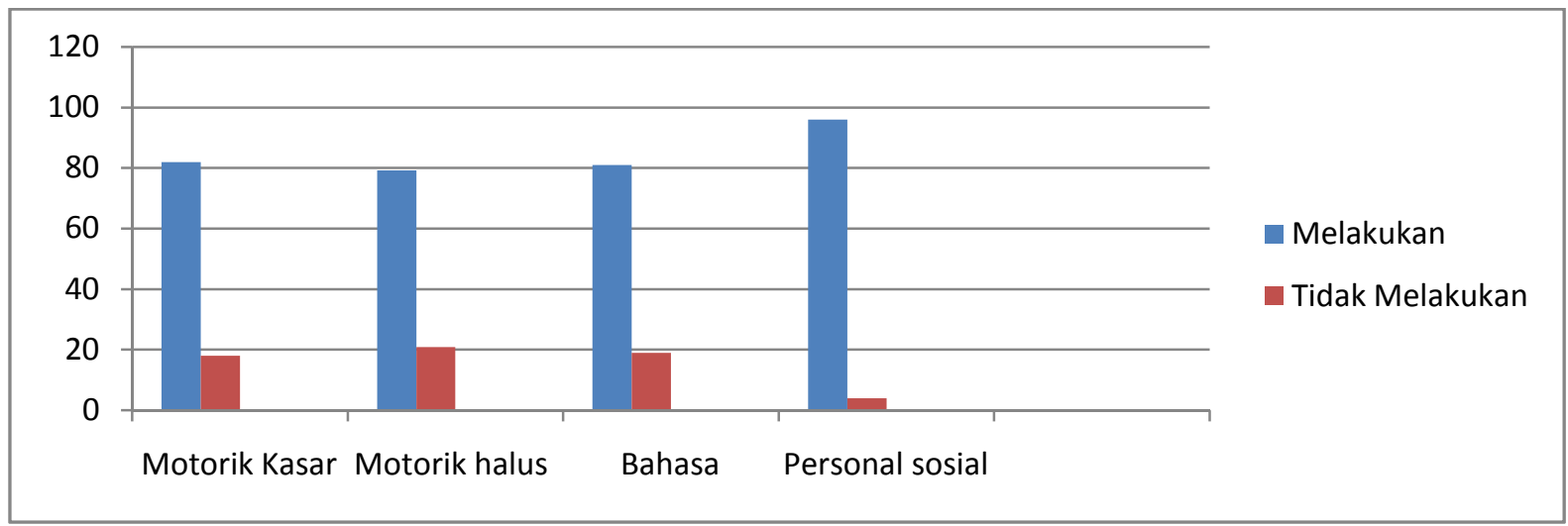

Gambar 3.

Persentase Perilaku Stimulasi perkembangan Anak Usia 4-6 Tahun 
Stimulasi perkembangan anak usia 4-6 tahun memiliki perilaku baik dalam menstimulasi anaknya yaitu $>75 \%$ responden sudah melakukan stimulasi pada anak baik motorik kasar, motorik halus, bahasa dan personal sosial.

\section{PEMBAHASAN}

Hasil penelitian menunjukkan bahwa bahwa rata-rata usia Ibu yaitu 32tahun, usia ibu terendah terendah 24 tahun dan usia ibu tertua 40 tahun. Sementara usia ayah rata-rata yaitu34tahun ,usia ayah terendah terendah 27 tahun dan usia ayah tertua 46 tahun. Hal ini menunjukkan bahwa usia orang tua merupakan usia produktif.

Usia mampu mempengaruhi pengetahuan seseorang. Bertambahnya umur seseorang dapat berpengaruh pada pertambahan pengetahuan yang diperolehnya, akan tetapi pada usia tertentu atau menjelang usia lanjut kemampuan mengingat atau penerimaan suatu pengetahuan akan berkurang (Notoatmodjo, 2008). Sementara menurut Hurlock (2014) semakin cukup umur, tingkatkematangan dan kekuatan seseorang akan lebih matang dalam berfikir danbekerja. Pada penelitian ini ratarata usia Ibuyaitu32tahun dan usia ayah ratarata yaitu34tahun dengan pengetahuan tentang stimulasi perkembangan anak usia 0-6 tahun sebagian besar baik. Hal ini menunjukkan bahwa pada usia ini orang tua sudah cukup matang dalam berfikir dan bekerja sehingga orang tua cenderung memiliki pengetahuan baik. Namun tidakselaluorang tua dengan usia yang lebih tua memiliki tingkatpengetahun yang lebih tinggi, hal ini dapat disebabkan karena orang tua tidakmemilki pemahaman yangcukup, kurangnya pengalaman dan informasi yang diperolehnya (Helmi, Amatus, abram, 2013).

Hasil penelitian menunjukkan bahwa pekerjaan sebagian besar ibu memiliki pekerjaan yaitu sebanyak 36 responden $(55,4 \%)$ dan ayah yang bekerja yaitu 54 responden $(83,1 \%)$. Hal ini menunjukkan bahwa sebagian besar responden bekerja. Selain faktor pendidikan, faktor pekerjaan juga berpengaruh terhadap pengetahuan seseorang. Menurut (Wawan dan Dewi, 2010). bekerja bagi orang tua akan mempunyai pengaruh terhadap kehidupan keluarga, seseorang yang sudah bekerja maka tingkat kemampuan berfikirnya akan berpengaruh terhadap pengetahuan. Dari hasil penelitian sebagian besar ayah dan ibu memiliki pekerjaan. Mayoritas pengetahuan orang tua dalam penelitian ini adalah baik. Dengan pekerjaan yang dimiliki, responden banyak berinteraksi dengan lingkungan dan warga sekitar. Hal ini juga akan mempengaruhi informasi yang diperolehnya misalnya pengetahuan mengenai stimulasi perkembangananakusia0-6tahun.

Hasil penelitian menunjukkan bahwa dari 65 orang tua sebagian besar ibu berpendidikan SMA 54 orang $(83,1 \%)$, dan pendidikan ayah sebagian besar SMA 53 orang $(81,5 \%)$. Hal ini menunjukan bahwa orang tua memiliki pendidikan menengah. Seseorang dengan pendidikan menengah diharapkan memiliki pemahaman yang baik mengenai stimulasi perkembangan anak usia 0-6 tahun. Faktor lain yang mempengaruhi pengetahuan seseorang yaitu faktor pendidikan. Tingkat pendidikan akan berpengaruh dalam memberi respon yang datang dari luar, seseorang yang lebih tinggi pendidikannya maka pengetahuannya akan semakin luas (Wawan dan Dewi, 2010)

Hasil penelitian menunjukkan bahwa sebagian besar orang tua memiliki perilaku baik tentang stimulasi perkembangan anak usia 0-6 tahun yaitu sebanyak 56 responden $(86,2 \%)$ dan sebagian kecil yang memiliki perilaku cukup yaitu sebanyak 9 responden $(13,8 \%)$. Stimulasi perkembangan merupakan kegiatan merangsang kemampuan dasar anak usia 0-6 tahun agar anak dapat tumbuh dan berkembang secara optimal (Depkes RI, 2009). Anak yang kurang mendapat stimulasi dapat mengalami penyimpangan tumbuh kembang atau bahkan gangguan secara menetap. Stimulasi pada anak dapat dilakukan oleh orang tua, pengasuh, keluarga atau orang-orang yang berada di sekitar anak. Stimulasi yang diberikan dapat berupa verbal, auditori, visual, taktil, dan lainlain (Susanto, 2011). Hasil Khususnya hal ini menunjukkan bahwa orang tua sudah tahu cara melakukan stimulasi kepada anaknya. Dalam perilaku ini dibagi menjadi 3 tahapan umur yaitu 0-1 tahun, 1-3 tahun dan 4-6 tahun, dari ketiga tahapan umur tersebut $>75 \%$ seluruh orang tua sudah melakukan stimulasi pada anak baik motorik kasar, motorik halus, bahasa dan personal sosial.

\section{SIMPULAN DAN SARAN Simpulan}

1. Rata-rata usia ibu 32 tahun dan usia ayah 34 tahun. Sebagian besar ibu dan ayah 
memiliki pekerjaan. Sementara berdasarkan pendidikan sebagian besar ibu dan ayah berpendidikan SMA

2. Perilaku orang tua dalam stimulasi perkembangan anak usia 0-6 tahun di bagi menjadi 3 yaitu pada perilaku orang tua yang memiliki anak pada umur 0-1 tahun, umur 1-3 tahun dan umur 4-6 tahun dari ketiga tahapan umur memilki hasil yaitu sebanyak 56 responden $(86,2 \%)$ dan sebagian kecil yang memiliki perilaku cukup yaitu sebanyak 9 responden $(13,8 \%)$.

\section{Saran}

Diharapkan orangtua untuk mencari informasi tentang stimulasi perkembangan anak usia 0-6 tahun dengan jalan sering membaca buku, majalah, membuka internet bertanya kepada tenaga kesehatan, kader posyandu pada saa pelayanan posyandu, teman, atau keluarga untuk dapat menstimulasi perkembangan anak usia 0-6 tahun akan meningkat.

Hasil penelitian ini disarankan dapat digunakan sebagai dasar awal untuk melanjutkan penelitian dibidang sama dengan variable penelitian lain yang belum diungkap sehingga didapatkan hasil atau informasi yang lebih luas dan lengkap. Misalnya mempertimbangkan untuk menambah variable faktor yang mempengaruhi perilaku orang tua dalam stimulasi perkembangan anak seperti pengetahuan orangtua dukungan tenaga kesehatan, dukungan keluarga, tokoh masyarakat, social budaya, status ekonomi, dan pengalaman.

\section{DAFTAR PUSTAKA}

Arikunto, S (2010). Prosedur Penelitian :Suatu Pendekatan Praktik. (EdisiRevisi). Jakarta : RinekaCipta.

Cahyaningrum (2013). Hubungan Antara Pengetahuan Ibu Tentang Stimulasi Dengan Tingkat Perkembangan Pada Anak Usia 3-5 Tahun di Kelurahan Kranggan Temanggung. Naskah Publikasi. Sekolah Tinggi Ilmu Kesehatan 'Aisyiyah Yogyakarta.

Depkes RI,( 2009). Sistem Kesehatan Nasional. Jakarta.

Depkes (2012). Survei Demografi dan Kesehatan Indonesia 2012.http://www.bkkbn.go.id/litbang/pu sdu/HasilPenelitian/SDKI2012/Laporan
PendahuluanSDKI 2012.pdf. Diakses tanggal 10 Mei 2013

Donna L. Wong...[et.al]. (2008). Buku Ajar Keperawatan Pediatrik Wong. Alih bahasa : Agus Sutarna, Neti. Juniarti, H.Y. Kuncoro. Editor edisi bahasa Indonesia : Egi Komara Yudha....[et al.]. Edisi 6. Jakarta : EGC

Fadlyana E. dan Larasaty S. (2009). Pernikahan Dini dan Permasalahannya. Sari Pediatri. Vol. 11, No. 2, Agustus 2009.

Farah, J. M. (2008). Environmental stimulation, parental nurturance and cognitive development in humans. Journal Developmental Science Vol 11, No.5, 793-801. doi: 10.1111/j.1467 7687.2008.00688.

http://www.psych.upenn.edumfarah/Dev elopment Enviro Stim Pare ntalNurt .pdf. (diakses tanggal 27 Maret 2018)

Guyton, Hall JE.(2007). Buku Ajar Fisiologi Kedokteran (Terjemahan). 11 ed. Rachman RY, Hartanto H, Novrianti A, Wulandari N, editors. Jakarta: EGC; P. 423-35

Harlimsyah. (2007). Aspek-Aspek Pertumbuhan dan Perkembangan. Jakarta: EGC

Hidayat AA, (2008) metode penelitian kebidanan teknik analisis data. Salemba medika.

Hidayat A.A., (2010). Metode Penelitian Kesehatan Paradigma Kuantitatif, Jakarta: Heath Books

Hurlock (2014). Psikologi Perkembangan Suatu Pendekatan SepanjangRentangKehidupan. Jakarta: Erlangga

Irawan, S. (2014). Gambaran Perilaku Ibu Dalam Menstimulasi Perkembangan Motorik Anak Toddler Di Pendidikan Anak Usia Dini Mekarsari Pucangombo Tegalombo Pacitan. Naskah Publikasi. Prodi keperawatan. Universitas Muhammadiyah Surakarta. 
Kerlinger. (2006). Asas-Asas Penelitian Behaviour. Edisi 3, Cetakan 7. Yogyakarta:Gadjah Mada University Press

Kosegeran, H. B. (2013). Hubungan Tingkat Pengetahuan Orang Tua Tentang Stimulasi Dini Denganperkembangan Anak Usia 4-5 Tahun di Desa Ranoketang Atas. ejournal keperawatan (e-Kp) Volume 1. Nomor 1. Agustus 2013.

Marischa, S. (2016). Hubungan Pengetahuan Orang Tua Tentang Stimulasi Dengan Perkembangan Motorik Kasar Anak Usia 0 - 5 Tahun Di Desa Bumi Aji Kecamatan Anak Tuha Kabupaten Lampung Tengah. Skripsi. Universitas Bandar Lampung.

Narendra, M.S, dkk. (2002). Buku Ajar I Tumbuh Kembang Anak dan Remaja Edisi Pertama IDAI. Jakarta : Sagung Seto

Notoatmodjo, Soekidjo (2007). Pendidikan dan Perilaku kesehatan.Cetakan 2 Jakarta: PT. Rineka Cipta.

Notoarmodjo, Soekidjo. (2010). Metode Penelitian Kesehatan. Jakarta : Rineka Cipta

Nursalam. (2003). Konsep Penerapan Metodologi Penelitian Ilmu Keperawatan.

(Edisi Pertama). Jakarta: Salemba Medica

Nursalam, (2008). Konsep dan Penerapan Metodelogi Penelitian Ilmu Keperawatan. Jakarta : Salemba Medika

Nuryanti, Lusi. (2008). Psikologi Anak. Jakarta: PT Indeks

Santrock, jhon.W. (2012).life span development. 13th edition.unuvercity of texas, dallas: Mcgraw hill

Siagian, P. Sondang (2010). Manajemen Sumber Daya Manusia. Jakarta : Bumi Aksara

Soetjiningsih (1998). Tumbuh kembang. Jakarta :EGC
Soetjiningsih. (2007).Tumbuh Kembang Anak. Surabaya: Penerbit Buku Kedokteran.

Sugiyono, (2007). Metode Penelitian Kuantitatif Kualitatif dan $R \quad \& \quad D$. Bandung: Elfabeta

Sugiyono, (2009), Metode Penelitian Kuantitatif, Kualitatif dan $R \& D$, Bandung : Alfabeta.

Susanto, Ahmad. (2011). Perkembangan Anak Usia Dini. Edisi 1. Jakarta. Prenada Media Group.

Susilaningrum, R. (2013). Asuhan Keperawatan Bayi dan anak untuk Perawat danBidan Edisi 2. Jakarta: Salemba Medika

Sulistyawati, A. (2014). Deteksi Tumbuh Kembang Anak. Jakarta Selatan : Salemba Medika

Supartini.(2015).Hubungan Pemberian ASI Ekslusif Dengan Perkembangan

Motorik Kasar Pada Anak Usia 6-36 Bulan. Jurnal Kebidanan. 2015;5.Epub maret 2015 .

Swarjana, LK. (2016), Metode Penelitian Kesehatan (edisi revisi), Yogyakarta: ANDI

Udiyono, Ari. (2007). Metodologi Penelitian Kesehatan. Semarang: Badan Penerbit Universitas Diponegoro.

Wawan A \& Dewi N., 2010. Teori dan Pengukuran Pengetahuan, Sikap, dan Perilaku Manusia. Yogyakarta: Nuha Medika

Wong, L. Donna. 2009. Buku Ajar Keperawatan Pediatrik. Vol. 1. Edisi 6. . Jakarta:EGC. 